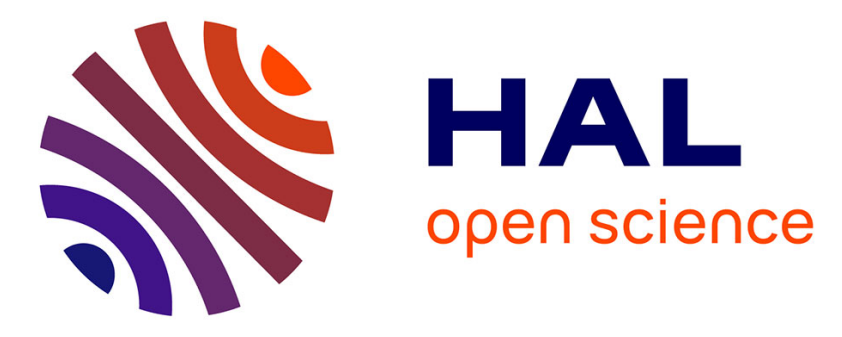

\title{
Discriminating small wooded elements in rural landscape from aerial photography: a hybrid pixel/object-based analysis approach
}

David Sheeren, Gary N. Bastin, Annie Ouin, Sylvie Ladet, Gerard Balent, Jean-Paul Lacombe

\section{To cite this version:}

David Sheeren, Gary N. Bastin, Annie Ouin, Sylvie Ladet, Gerard Balent, et al.. Discriminating small wooded elements in rural landscape from aerial photography: a hybrid pixel/object-based analysis approach. International Journal of Remote Sensing, 2009, vol. 30 (19), pp.4979-4990. 10.1080/01431160903022928 . hal-00745845

\section{HAL Id: hal-00745845 \\ https://hal.science/hal-00745845}

Submitted on 7 Dec 2012

HAL is a multi-disciplinary open access archive for the deposit and dissemination of scientific research documents, whether they are published or not. The documents may come from teaching and research institutions in France or abroad, or from public or private research centers.
L'archive ouverte pluridisciplinaire HAL, est destinée au dépôt et à la diffusion de documents scientifiques de niveau recherche, publiés ou non, émanant des établissements d'enseignement et de recherche français ou étrangers, des laboratoires publics ou privés. 


\section{OATAO}

Open Archive Toulouse Archive Ouverte

\section{Open Archive TOULOUSE Archive Ouverte (OATAO)}

OATAO is an open access repository that collects the work of Toulouse researchers and makes it freely available over the web where possible.

This is an author-deposited version published in : http://oatao.univ-toulouse.fr/ Eprints ID : 6791

To link to this article : DOI:10.1080/01431160903022928

URL : http://dx.doi.org/10.1080/01431160903022928

\section{To cite this version :}

Sheeren, David and Bastin, N. and Ouin, Annie and Ladet, S. and Balent, G. and Lacombe, J.-P. Discriminating small wooded elements in rural landscape from aerial photography: a hybrid pixel/object-based analysis approach. (2009) International Journal of Remote Sensing, vol. 30 ( $\left.\mathrm{n}^{\circ} 19\right)$. pp. 4979-4990. ISSN 01431161

Any correspondance concerning this service should be sent to the repository administrator: staff-oatao@inp-toulouse.fr. 


\title{
Discriminating small wooded elements in rural landscape from aerial photography: a hybrid pixel/object-based analysis approach
}

\author{
D. SHEEREN ${ }^{*} \dagger$, N. BASTIN $\dagger$, A. OUIN $\dagger$, S. LADET $\$$, G. BALENT $\ddagger$ and \\ J.-P. LACOMBE $\dagger$ \\ †Université de Toulouse, INPT-ENSAT, UMR 1201 Dynafor, BP 32607, 31326 Castanet \\ Tolosan Cedex, France \\ †INRA, UMR 1201 Dynafor, BP 52627, 31326 Castanet Tolosan Cedex, France
}

*Corresponding author. Email: david.sheeren@ensat.fr

\begin{abstract}
While small, fragmented wooded elements do not represent a large surface area in agricultural landscape, their role in the sustainability of ecological processes is recognized widely. Unfortunately, landscape ecology studies suffer from the lack of methods for automatic detection of these elements. We propose a hybrid approach using both aerial photographs and ancillary data of coarser resolution to automatically discriminate small wooded elements. First, a spectral and textural analysis is performed to identify all the planted-tree areas in the digital photograph. Secondly, an object-orientated spatial analysis using the two data sources and including a multi-resolution segmentation is applied to distinguish between large and small woods, copses, hedgerows and scattered trees. The results show the usefulness of the hybrid approach and the prospects for future ecological applications.
\end{abstract}

\section{Introduction}

The importance of green veining in agricultural landscapes has already been demonstrated for soil and biodiversity conservation (Grashof-Bokdam and Langevelde 2005). Green veining, which consists of semi-natural elements such as pond, permanent meadows, field margin, hedgerows and woodlots embedded in crop mosaics, helps to maintain wildlife biodiversity (auxiliary, game) in rural landscapes. Among these semi-natural elements, the identification and characterization of small wooded objects (i.e. copses, hedgerows and scattered trees) are often required in landscape ecology studies: for instance, to predict the response of passerine bird abundance to landscape structure and composition (Balent and Courtiade 1992), or to identify landscape elements and configurations that encourage auxiliary hoverflies (Sarthou et al. 2005).

Although there is a growing interest in small wooded elements and their role in ecological processes, landscape ecology studies suffer from the lack of operational methods for automatic detection of these elements from aerial photographs. Several investigations have already been carried out regarding the extraction of areas of vegetation or anthropogenic objects (buildings, roads) from remotely sensed data (Baltsavias 2004, Boyd and Danson 2005). However, most of the studies related to the identification of wooded elements have been devoted to the classification of large forest patches often with some refinements regarding tree species or boundary 
delineation (e.g. Peterson et al. 2004, Tuominen and Pekkarinen 2005). The automatic detection of natural, small wooded and thin linear elements in rural landscapes and their differentiation when they are connected but do not underpin the same ecological processes (e.g. adjacent hedges and woods) has drawn less attention (Stach et al. 2006, Thornton et al. 2006, Zhang et al. 2006). Because of the fine spatial resolution, largescale aerial photographs are preferred to identify such elements by applying computer-aided interpretation techniques. However, this approach is generally time-consuming and, thus, expensive and not recommended when investigating large areas. In addition, the spectral information provided by this kind of data is not always sufficient to obtain classifications of high accuracy. It often requires adding texture into the classification step. Medium and high spatial resolution remotely sensed data (e.g. SPOT and Landsat Thematic Mapper (TM) images) are also widely used to identify wooded areas. These data provide richer spectral information and cover larger areas. However, the relatively coarse spatial resolution $(\geq 20 \mathrm{~m} \times 20$ $\mathrm{m})$ does not enable detection of all small wooded fragments such as copses, hedgerows and scattered trees.

Since the availability of very high spatial resolution satellite images, object-based image analysis (OBIA) has been proposed as an alternative to the pixel-based classification approaches (Benz et al. 2004). It involves segmenting images into homogeneous regions and characterizing objects with a set of features related to spectral, spatial and contextual properties. Because these image segments represent objects in the landscape more accurately than the original pixels, and classify them according to their shapes and sizes, this approach is well suited for the extraction of small wooded elements. In addition, previous studies have shown that object-based methods outperform pixel-based methods when applied to aerial photographs (e.g. Cleve et al. 2008). However, segmentation in objectbased classification is still a crucial task. The user must decide the specific scale at which an image is to be segmented into objects and this scale can vary from one class to another. Scales are often difficult to define and parameter values are highly dependent on the user's experience. In that sense, a hybrid pixel/object-based classification may be less dependent on the results of the segmentation. Such a hybrid approach has already been proposed with success. Among the few recent researches in this area, Wang et al. (2004) integrated the pixel and object-based classification for mapping mangroves from IKONOS imagery. Shackelford and Davis (2003) adopted a hybrid fuzzy approach for urban land-cover classification. Other works presented a similar method for shape-based object recognition: Li et al. (2006) for geophysical phenomena detection and Carmichael and Herbert (2004) for computer vision applications. In general, two main conclusions can be drawn from the above studies.

1. A more accurate classification can be achieved with a hybrid approach: a pixelbased classification can be applied for classes with good separability while an object-based analysis can be performed to better discriminate spectrally mixed classes.

2. A more accurate segmentation can also be obtained: the classified pixel-level can serve to optimally segment the individual objects of interest.

In this paper, we propose a hybrid method coupling a pixel-based classification approach to extract woody elements in the landscape using texture from aerial photographs and an object-based image analysis to discriminate among the different wooded element types: large and small woods, copses, hedgerows and scattered trees. 


\section{Material}

The study area is included in the territory of the Long-Term Ecological Research (LTER-Europe) study site 'Valleys and Hills of Gascogne' (VHG), France (431' $\mathrm{N}$, $0^{\circ} 52^{\prime} \mathrm{E}$ ). It is an agricultural landscape typical of south-western France (agricultural mosaic with wooded patches) with mixed production systems, i.e. livestock farming systems and cropping systems. The total area of the study site is approximately 25000 ha and includes a meso-scale watershed (12 000 ha) - the Nère river.

The major data used for the study were a mosaic of orthorectified digital aerial true colour photographs acquired in 2002 (named BDORTHO ${ }^{\circledR}$ ) and produced by the French mapping agency (IGN). This set of geo-referenced photographs covers approximately $31 \mathrm{~km}^{2}$ and has a spatial resolution of $0.5 \mathrm{~m} \times 0.5 \mathrm{~m}$. Infrared (IR) orthophotos which are more appropriate for extracting wooded elements also exist for this study site. However, these data have not been used, the most recent date being 1996 which is too remote to combine with the present ecological data. In addition, the structure of the agricultural land has since been modified and has led to the disappearance of some hedges.

Additional data were also used to discriminate wooded areas during the objectorientated analysis, especially to disconnect hedgerows from wood patches. These data are a binary wood/non-wood image derived from an existing supervised landcover classification (Barreau 2003). This classification was based on four SPOT-4 multi-spectral (MS) multi-temporal images acquired in 2001 (January, April, July and October) with a spatial resolution of $20 \mathrm{~m} \times 20 \mathrm{~m}$. In a general way, any source of data of the same period providing a wood/non-wood map with coarser resolution (i.e. $>10 \mathrm{~m} \times 10 \mathrm{~m}$ ) can be used as ancillary data in the method (e.g. the CORINE Land Cover map or the Pan-European Forest/non-Forest map proposed by the EU-Joint Research Centre (Pekkarinen et al. 2009)).

\section{Method}

The hybrid method we propose has two main steps: (1) a spectral and textural pixelbased analysis to get all the wooded elements of the study area and (2) a spatial objectbased analysis to delineate the different wooded element types: small and large woods, copses, scattered trees and linear elements (figure 1). Data pre-processing was performed to ensure accurate geometrical correspondence between the two sources of data: the true-colour photograph and the binary wood/non-wood mask extracted from the available land-cover classification. In addition, the digital photograph was resampled to a pixel size of $1 \mathrm{~m} \times 1 \mathrm{~m}$ for optimal running time computation during textural analysis and segmentation. The pixel-based image analysis was conducted using the resampled digital photograph mosaic.

\subsection{Pixel-based image analysis: extraction of wooded elements}

3.1.1 Textural analysis. Texture is the expression of local variations in grey-levels in the pixels of the digital image that result from the particular organization of objects in the landscape (Haralick et al. 1973). Several studies demonstrated interest in incorporating such spatial information into classification procedures to improve classification accuracy. The addition of texture has become quite common for land-cover mapping (Marceau et al. 1990, Puissant et al. 2005). It has been also widely used in forestry and ecological mapping applications (St Onge and Cavayas 1995, Franklin 


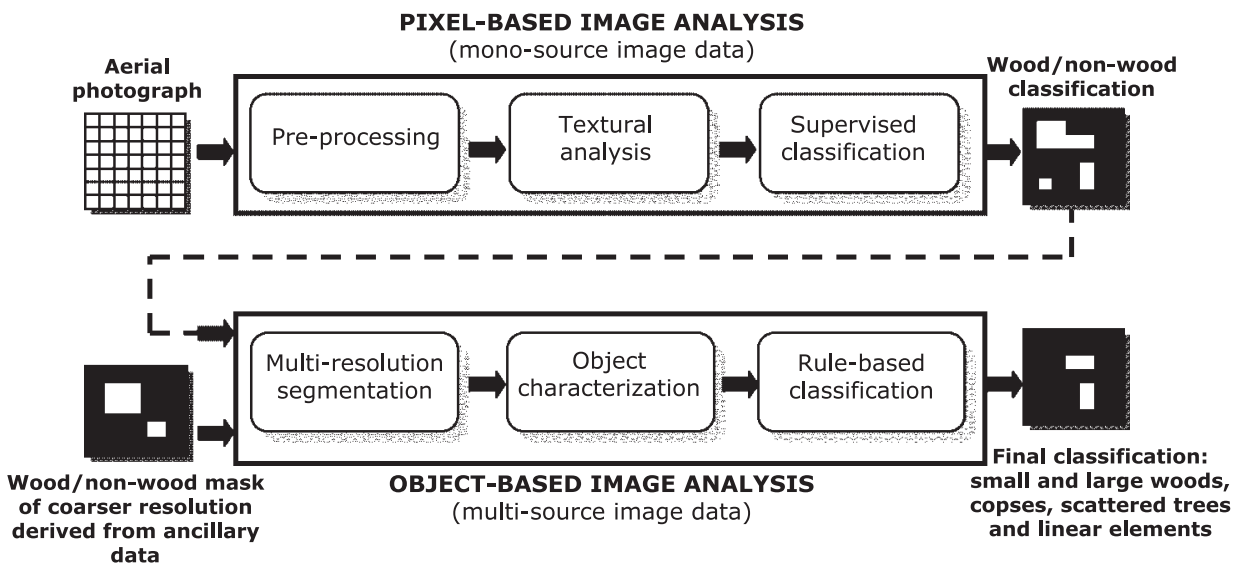

Figure 1. Flowchart of the method proposed to discriminate small wooded elements in rural landscape. A pixel-based image analysis is performed to extract wooded objects from truecolour photography. An object-based analysis is applied in the next step using the result of the previous step and an additional wood/non-wood map with coarser resolution, to enhance the thematic resolution of the pixel-based classification and disconnect objects related to different ecological processes.

et al. 2000, Coburn and Roberts 2004), especially when digital aerial photographs are required (Wulder et al. 1998, Caridade et al. 2007). Generally, the resolution of aerial photographs is finer than or similar to the size of the trees in the image. Thus, local variations in the pixels can be related to forest structure variables (Tuominen and Pekkarinen 2005, Kayitakire et al. 2006).

In this study, the textural information is not used for estimating wood attributes (e.g. species, height and density). The texture is used mainly to extract all the wooded elements from the orthophotos more efficiently and limit confusion with other classes that have similar pixel values (e.g. grasslands and crop fields). Since the further supervised classification step can be performed without this information, the textural analysis - which is time consuming - can be viewed as an optional step in the method. However, as illustrated in the results, adding this information contributes to considerable improvement in the classification accuracy.

There are several approaches to texture processing. The most widely used in remote sensing is based on the grey-level co-occurrence matrix (GLCM) proposed by Haralick et al. (1973). This matrix computes the relationships of pixel values from which various second-order statistical texture measures can be derived (Haralick 1979). Several parameters must be defined for computation of the GLCM: the size of the moving window, and offset distance and direction.

In our case, height texture measures were computed from the green band of the aerial photograph: dissimilarity, contrast, homogeneity, variance, entropy, correlation, angular second moment and mean. This set of measures was chosen with the intent of not selecting arbitrarily just a few of them. The 8-bit image (256 grey levels) was rescaled into 32 grey levels to ensure statistical validity of the measures (Clausi 2002) and to reduce the computation time of the GLCM (which is proportional to $2^{n}$ where $n$ is the number of bits). Four main directions $\left(0^{\circ}, 45^{\circ}, 90^{\circ}, 135^{\circ}\right)$ and three window sizes $(3 \times 3,7 \times 7,11 \times 11)$ were used with a constant offset distance of one pixel. The combination of all GLCM parameter values produced 96 texture images. 


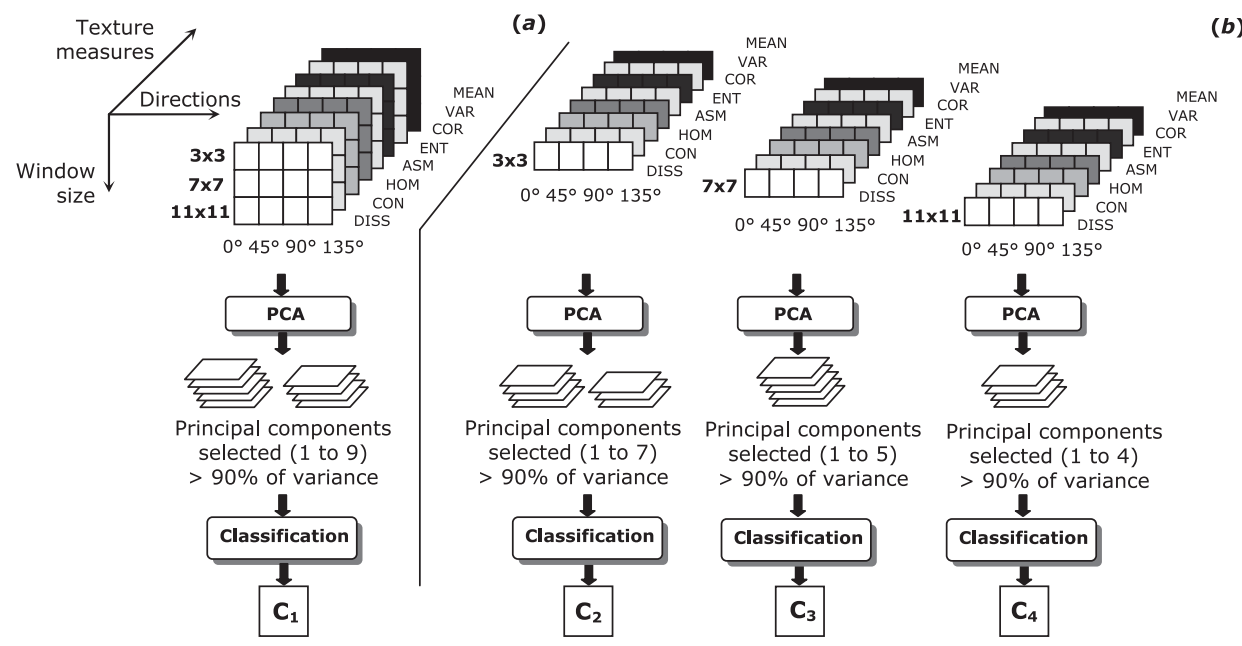

Figure 2. The classification strategies tested to assess the usefulness of adding texture. Each cell of the matrix represents one texture image related to one texture measure (DISS, dissimilarity; CON, contrast; HOM, homogeneity; ASM, angular second moment; ENT, entropy; COR, correlation; VAR, variance; MEAN), one window size and one direction. In the first strategy $(a)$, a principal component analysis (PCA) was computed using all the texture variables including all the window sizes and directions. In the second strategy $(b)$, a PCA was applied on each set of texture variables related to one window size and including all directions.

Finally, to reduce the number of the texture images computed and decorrelate them without decreasing the main textural information, standardized principal component analyses (PCA) based on correlation matrices were performed following two different strategies (figure 2). The strategies were tested to compare their performance and to identify a possible optimal window size for wooded objects with the understanding that the success of the classification procedure using textural measures depended largely on the selected window size (Puissant et al. 2005). In the first strategy (figure 2(a)), a PCA was applied on all the texture variables including the different window sizes and directions. In the second strategy (figure 2(b)), a PCA was computed for each set of texture variables related to only one window size including each direction. With each strategy, more than $90 \%$ of the textural information was conserved within the principal components retained for the classification.

3.1.2 Classification and post-processing. Several classifications were performed following the different strategies (see $\mathrm{C}_{1}, \mathrm{C}_{2}, \mathrm{C}_{3}, \mathrm{C}_{4}$ in figure 2). The principal components were added to the $\mathrm{R}-\mathrm{G}-\mathrm{B}$ bands of the digital photograph to extract all the wooded areas and obtain a binary mask (i.e. the planted/non-planted-tree mask mentioned in the next section). The standard maximum likelihood classifier (MLC) was applied using training site data derived from visual interpretation. In the next post-classification step, the resulting mask was filtered to reduce the salt-and-pepper effect in the image and to join some disconnected planted-tree elements within the woods. First, a major analysis with a window size of $9 \times 9$ was performed on pixels classified as planted-tree areas. Then, the same filter was applied successively on nonplanted-tree areas in an iterative way until all the wood patches were filled in. This selective post-processing enabled some classification artefacts to be corrected without 
substantial alteration of the borders of the wooded elements. Finally, classification $\mathrm{C}_{1}$, which proved to be the best, was retained for the following object-orientated image analysis.

\subsection{Object-based image analysis: discrimination between wooded element types}

A spatial analysis based on the object-orientated approach was performed to get more details in the planted-tree areas class and to disconnect some merged elements that were semantically different and related to different ecosystems (in particular, the woody fragments and the hedgerow network). This analysis was carried out following the OBIA methodology composed of three steps: segmentation, object characterization, classification. These steps are described in detail in the following sections.

3.2.1 Multi-resolution segmentation. Image objects were created from the binary mask obtained in the previous step using the multi-resolution segmentation method proposed by Definiens Software (eCognition). The segmentation algorithm introduced by Baatz and Schäpe (2000) is a bottom-up region-growing technique which merges stepwise adjacent pixels according to their similarity. Two pixels are merged to form larger segments if the resulting segments do not exceed a user-defined heterogeneity threshold. The definition of heterogeneity includes both spectral and spatial criteria and is fixed by the 'scale parameter'. Distinct weights can be assigned to the data layers used in the segmentation process.

In this study, segmentation was conducted at two levels using different scale parameters to construct a hierarchical image object network. The first level (level 1) was created with a scale parameter fixed at 200 using only the spectral heterogeneity criterion related to the binary mask composed of the planted/non-planted-tree classes (weight $=1$ ). The $\mathrm{R}-\mathrm{G}-\mathrm{B}$ bands of the digital photograph were not used at this level (weight $=0$ ). In this way, all the pixels classified in the binary mask were aggregated and transformed into image objects with boundaries strictly identical to the classes at the pixel level. In the second step, a lower level (level 2) was created with a scale parameter of 50 using both spectral and spatial heterogeneity criteria. This level was processed from the three visible bands of the aerial photograph (weight $=1$ ) but without using the binary mask of planted-tree areas (weight $=0$ ). The sub-objects created at this level with finer segmentation enabled disconnected elements to be merged at the higher level (e.g. adjacent woods and hedges).

It is important to note that the method is not very sensitive to the scale parameter values defined for the multi-resolution segmentation. At segmentation level 1, the scale value must be sufficiently high to avoid an over-segmentation of the pixel-based classification. This condition does not cause any difficulty since the segmentation is performed on the binary mask of the planted/non-planted area classes. On the contrary, at segmentation level 2, the scale value must be relatively low to over-segment the aerial photograph and disconnect elements belonging to different classes.

3.2.2 Class definition and image object characterization. The image objects were characterized with different features according to the classes we wanted to extract. The class hierarchy defined for this study is presented in figure 3. For level 2 classification, we defined two classes of woody areas: classes ' $A$ ' and ' $B$ '. The first included the wooded elements classified as planted-tree areas in both the data sources (i.e. the planted-tree areas of the level 1 segmentation derived from the aerial photograph and the wooded/non-wooded areas derived from the existing land-cover 




Figure 3. Image object class hierarchy based on the IFN typology. Woody areas 'A' are plantedtree areas in both the aerial photograph and the wood/non-wood mask with coarser resolution derived from an existing land-cover classification. Woody areas ' $\mathrm{B}$ ' include the planted-tree areas that exist only in the photograph.

classification of the $20 \mathrm{~m} \times 20 \mathrm{~m}$ resolution SPOT images). Thus, this class 'A' contained mainly large planted-tree areas but not the small fragments of woods and hedges that did not appear in the data with coarser resolution. These small objects were represented in class ' $\mathrm{B}$ ', which included the planted-tree areas that only existed in the aerial photograph (i.e. in segmentation level 1). The definitions adopted for the child classes at level 2 were adapted from the French National Forest Inventory (IFN) typology. A woody area is classified as a 'large wood' if it covers more than 4 ha. The 'small wood' class includes areas of between 50 ares and 4 ha. The 'copse' class includes areas of between 5 and 50 ares. 'Scattered trees' are clumps of less than 5 ares and 'natural linear elements' are tree rows with a width of less than $25 \mathrm{~m}$ and a length of more than $25 \mathrm{~m}$. In contrast to the IFN definitions, we did not take into account the average width at the top of the trees or the species composition in our definitions.

According to this typology, several spatial and relational features were computed to characterize the objects and to prepare the rule-based classification. The features selected were: area, length, width, compactness, elliptical fit and relation to superobjects. The wood/non-wood mask with coarser resolution derived from the landcover classification was imported as a raster thematic layer. The affiliation of the image objects to the thematic class of this layer was defined through a thematic attribute.

3.2.3 Rule-based classification. A rule-based classification composed of several steps concluded the object-orientated analysis. First, the image objects at segmentation level 1 were directly classified as planted-tree and non-planted-tree areas using the mask derived from the pixel-based analysis. Next, the image objects at the lower segmentation level (level 2) were processed to distinguish the woody areas 'A' and ' $\mathrm{B}$ ' within the planted-tree areas. Initially, woody areas labelled ' $A$ ' were identified using both the result of the previous classification (through the 'relational to super-object' feature) and the wood/non-wood thematic layer of the land-cover classification (through a corresponding 'thematic' attribute). Woody areas labelled ' $\mathrm{B}$ ' were extracted as a result. After this classification, the level 2 segmentation (in which the objects were over-segmented) was modified by merging all adjacent objects of the same class (classification-based fusion). This merging was undertaken to take into account the area criteria in the object recognition. The classification of the woody 


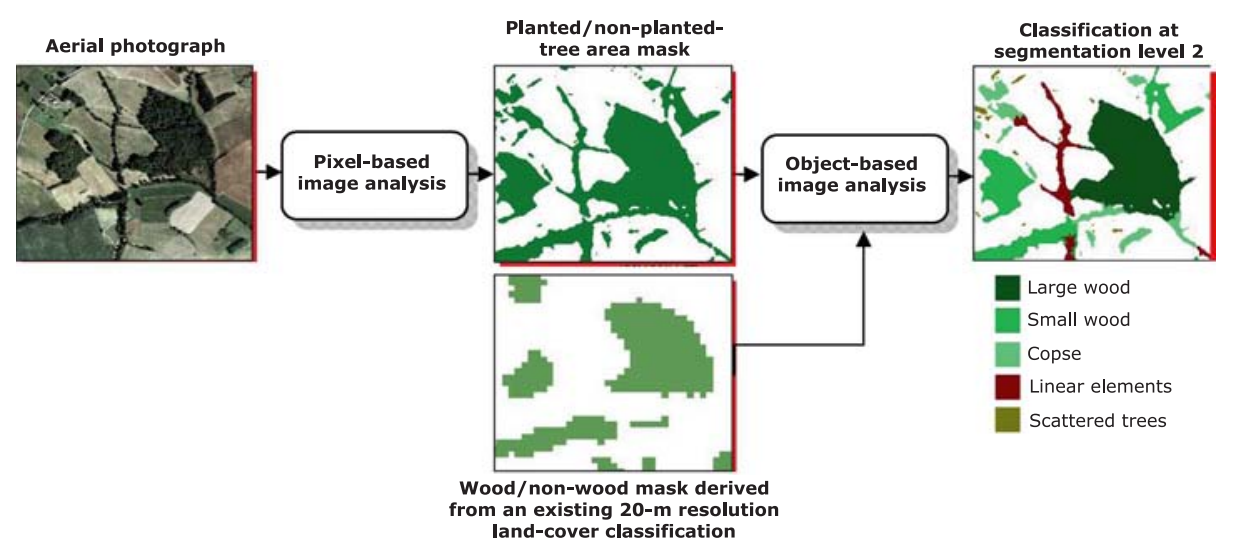

Figure 4. Excerpt of the pixel and object-based classifications.

areas 'A' and 'B' was then broken down into specialized classes (large wood, small wood, copse, scattered trees and linear elements) according to rules that had been defined previously.

This classification procedure was followed by a post-processing step to improve the results of the classification. Except for hedges, adjacent objects of the same or different classes (i.e. from different woody areas ' $A$ ' or 'B') were merged by keeping as class value the value of the largest woody object. For instance, if an object classified as copse ' $\mathrm{B}$ ' was adjacent to an object classified as small wood 'A', the resulting object was integrated in the small wood class ' $A$ ' after merging. If the area of the newly created object exceeded the maximum value associated with the definition of the resulting class, the object was integrated in the next higher-level woody class. In the previous example, the new object would be integrated in the large wood class ' $A$ ' if it was bigger than 4 ha. At the end of the process, the objects in class ' $A$ ' and ' $B$ ' were no longer distinguished (figure 4).

\subsection{Validation}

A visual interpretation of the digital photography was performed to obtain data for validation of the pixel and object classifications. More than 1\% (i.e. 330199 pixels) of the classified area was randomly selected to assess the accuracy of the pixel-based classification and 107 segments were retained in the case of the refined object-based classification. Accuracy assessment was based on the confusion matrix and associated indicators: overall accuracy and Kappa coefficient.

\section{Classification results and discussion}

A statistical summary of the results is presented for both the pixel-based and objectbased classifications (table 1). In a general way, the gain in thematic resolution with the object-based classification led to a loss in overall accuracy (from $92.6 \%$ for the best classification in the initial pixel-based analysis to $83.5 \%$ at the end of the object-based classification), due to the creation of some mixed objects during the segmentation. However, because the pixel-based and object-based analyses are sequential, the results of the two approaches should not be compared. In the case of the pixel-based analysis, 
Table 1. Summary statistics of the classification results.

\begin{tabular}{|c|c|c|c|c|c|c|c|c|c|c|c|}
\hline \multicolumn{6}{|c|}{ (a) Accuracy of the pixel-based analysis } & \multicolumn{6}{|c|}{ (b) Accuracy of the object-based analysis (\%) } \\
\hline & $\mathrm{C}_{0}$ & $\mathrm{C}_{1}$ & $\mathrm{C}_{2}$ & $\mathrm{C}_{3}$ & $\mathrm{C}_{4}$ & & LW & SW & $\mathrm{C}$ & $\mathrm{L}$ & ST \\
\hline & 79.50 & 92.61 & 86.90 & 92.13 & 91.72 & LW & 100 & 0.0 & 0.00 & 0.00 & 0.00 \\
\hline \multirow[t]{5}{*}{ Kappa } & 0.60 & 0.85 & 0.74 & 0.84 & 0.83 & SW & 0.00 & 91.30 & 0.00 & 3.03 & 0.00 \\
\hline & & & & & & $\mathrm{C}$ & 0.00 & 0.00 & 89.47 & 24.24 & 9.09 \\
\hline & & & & & & $\mathrm{L}$ & 0.00 & 8.70 & 10.53 & 63.64 & 9.09 \\
\hline & & & & & & ST & 0.00 & 0.00 & 0.00 & 9.09 & 81.82 \\
\hline & & & & & & OA $(\%)$ & \multicolumn{2}{|c|}{81.3} & \multicolumn{3}{|c|}{ Карра 0.76} \\
\hline
\end{tabular}

$\mathrm{C}_{0}$, without textural information; $\mathrm{C}_{1-4}$, with textural information; OA, overall accuracy; $\mathrm{LW}$, large wood; SW, small wood; C, copse; L, linear element; ST, scattered trees.

the accuracy assessment is related to the extraction of the planted-tree/non-plantedtree areas from the aerial photographs, with regard to textural information. For the object-based analysis, because the limits of the planted-tree area class have been definitively fixed at the previous step, only confusion errors involved in the discrimination between the wooded element types within the planted-tree area class are computed. The object-based classification results do not indicate confusion between the wooded element classes and the non-planted-tree areas.

In terms of proportions, the 'large wood' class represents $10.90 \%$ (342.53 ha) relative to the entire study area versus $3.27 \%$ (102.86 ha) for the 'small wood' class, $2.61 \%$ (82.21 ha) for the 'copse' class, $1.14 \%$ (35.90 ha) for the 'scattered trees' class, $3.44 \%$ (108.20 ha) for the 'linear elements' class and 78.63\% (2471.08 ha) for nonplanted-tree areas.

Concerning the pixel-based analysis, the addition of textural information always represented an important improvement in classification accuracy compared with the results obtained with the $\mathrm{R}-\mathrm{G}-\mathrm{B}$ classification alone. Without using the textural information, the overall accuracy was $79.5 \%$ with a $k$ coefficient of 0.60 (see $\mathrm{C}_{0}$ in table $1(a)$ ). There was considerable confusion between grasslands and cropped fields. Thus, even if the textural analysis is an optional step in the method, it is recommended to use this information to increase the accuracy degree of classification. Moreover, the pixel-based classification strategy that provided the highest accuracy included all the texture images in the PCA (i.e. $\mathrm{C}_{1}$ derived from nine principal components and the $\mathrm{R}-\mathrm{G}-\mathrm{B}$ bands) but the results were very similar to $\mathrm{C}_{3}$ and $\mathrm{C}_{4}$ (the difference was less than $1 \%$ ). It seems difficult to determine the most appropriate classification of these three cases. Concerning window size, the intermediate $7 \times 7$ dimension gave the most accurate results $\left(\mathrm{C}_{3}\right)$. The smaller dimension $(3 \times 3)$ was more suitable for the detection of small objects (scattered trees and thin linear elements) but shadows and planted-tree areas were mixed. The larger dimension $(11 \times 11)$ provided a classification that respected the object boundaries better but there were more omissions of small elements. Since the objects to be extracted are of different sizes, an intermediate window size may be optimal $\left(\mathrm{C}_{3}\right)$ or alternatively, a strategy that incorporates the three window sizes in the PCA $\left(\mathrm{C}_{1}\right)$, but this is more time-consuming. Finally, although the results of the classifications were not the same, overall accuracy was relatively high for each and provided a binary mask of planted/non-planted-tree areas of good quality. 

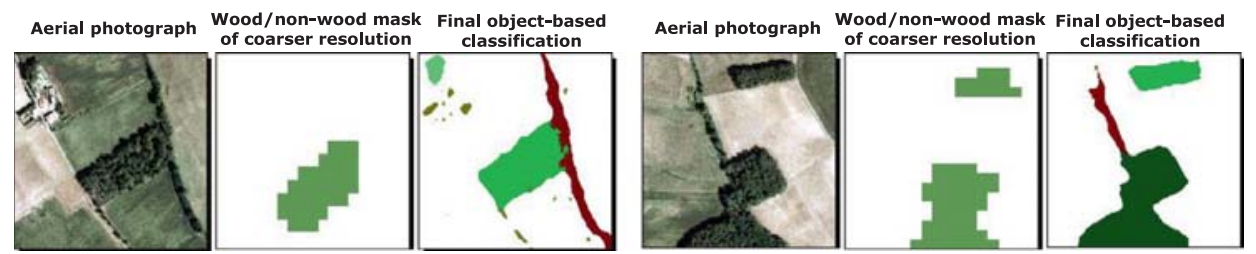

Figure 5. Disconnecting adjacent hedges and woods using a layer of woods with coarser resolution.

Concerning the object-based analysis, the results derived from the confusion matrix are given in table $1(b)$. For large and small woods, the classification was very accurate since the only criterion that distinguished the objects was area. However, for copses, linear elements and scattered trees, accuracy was moderate. There was confusion between classes due to segmentation errors. In some cases, hedgerows were difficult to extract because the linear character could not always be verified, especially when the hedges were interconnected. This created only one image object characterized by a complex shape which did not satisfy the previously defined classification rule. The shape property values get skewed. However, this issue is mitigated by ecological requirements. From the fauna point of view, hedges may be connected and form a continuous network throughout the landscape. The main challenge lies in distinguishing woods and hedges which do not underpin the same ecological processes (e.g. breeding versus mobility). Some adjacent hedges and wood patches are connected to form only one object which can introduce a confusion error. However, the use of the wood/non-wood mask with coarser resolution deriving from the existing land-cover classification means this aggregation effect can be limited. This is the main interest of using ancillary data in this hybrid method. At the lower segmentation level, the largest woody areas (class 'A') were classified using the two data sources. The smallest objects (including hedges) that did not appear in the $20 \mathrm{~m}$ land-cover classification because they were too small were identified in the digital photograph. Since the photograph is over-segmented at this segmentation level 2, adjacent hedges are not included in the class ' $A$ ' woody areas that border them. They can therefore be individualized (figure 5). The remaining aggregation errors mainly appeared between copses, scattered trees and hedges that were only extracted from the aerial photograph but, as mentioned previously, these errors are less critical because the objects concerned are related to the same ecosystems. In all cases, even when two sources can be used to classify the objects, all the object boundaries will be derived from the digital photograph (i.e. the data source with the greatest geometrical accuracy).

\section{Conclusion}

The aim of this study was to assess the potential usefulness of combining pixel-based and object-based image analysis using multi-source data to extract wood patches and linear elements in agricultural landscapes. Compared to the traditional per-pixel classification approach, the hybrid method enables the use of spatial and relational features during the classification process. This helps to discriminate between the different wooded element types based on their shape and size (large and small woods, copses, hedgerows and scattered trees). Compared to object-based image analysis, this approach contributes to classification results that are less dependent on the results of 
segmentation. Considering classification accuracy, the incorporation of texture measures in the pixel-based analysis proved to be the most reliable way to detect plantedtree areas from aerial photographs. The object-orientated classification could probably be improved by incorporating an intermediate segmentation level to reduce errors due to confusion between copses, scattered trees and linear elements. The assessment of the accuracy of this method could also be extended since the confusion matrix gives only information on the thematic accuracy but not on the geometrical accuracy of the image objects (i.e. the quality of segmentation). The resulting maps will now be used to calculate the fragmentation of wooded patches and connectivity indices. The morphological operators proposed by Vogt et al. (2007) to define forest spatial patterns are now being applied for this purpose.

\section{References}

BAATZ, M. and SchÄPE, A., 2000, Multiresolution segmentation: an optimization approach for high quality multi-scale image segmentation. In $12^{\text {th }}$ Angewandte Geographische Informationsverarbeitung (Karlsruhe: Herbert Wichmann Verlag), pp. 12-23.

Balent, G. and Courtiade, B., 1992, Modelling bird communities/landscape patterns relationships in a rural area of south-western France. Landscape Ecology, 6, pp. 195-211.

BALTSAVIAS, E.P., 2004, Object extraction and revision by image analysis using existing geodata and knowledge: current status and steps towards operational systems. ISPRS Journal of Photogrammetry and Remote Sensing, 58, pp. 129-151.

Barreau, G., 2003, Dynamique spatio-temporelle d'Episyrphus balteatus dans la forêt fragmentée des coteaux de Gascogne. Master thesis, DEA Ecologie des Systèmes Continentaux, University of Toulouse III.

Benz, U.C., Hofmann, P., Willhauck, G., Lingenfelder, I. and Heyen, M. 2004, Multiresolution, object-oriented fuzzy analysis of remote sensing data for GIS-ready information. ISPRS Journal of Photogrammetry and Remote Sensing, 58, pp. 239-258.

Boyd, D.S. and Danson, F.M., 2005, Satellite remote sensing of forest resources: three decades of research development. Progress in Physical Geography, 29, pp. 1-26.

Caridade, C.M.R., Marçal, A.R.S. and Mendonça, T., 2007, The use of texture for image classification of black \& white air photographs. International Journal of Remote Sensing, 29, pp. 593-607.

Carmichael, O.T. and Hebert, M., 2004, A hybrid object-level/pixel-level framework for shape-based recognition. In British Machine Vision Conference, A. Hoppe, S. Barman and T. Ellis (Eds.), 7-9 September, Kingston University, London (London: The Colour Works).

Clausi, D.A., 2002, An analysis of co-occurrence texture statistics as a function of grey-level quantization. Canadian Journal of Remote Sensing, 28, pp. 45-62.

Cleve, C., Kelly, M., Kearns, F.R. and Moritz, M., 2008, Classification of the wildlandurban interface: a comparison of pixel- and object-based classification using highresolution aerial photography. Computer, Environment and Urban Systems, 32, pp. 317-326.

Coburn, C.A. and Roberts, A.C.B., 2004, A multiscale analysis procedure for improved forest stand classification. International Journal of Remote Sensing, 25, pp. 4287-4308.

Franklin, S.E., Hall, R.J., Moskal, L.M., Maudie, A.J. and Lavigne, M.B., 2000, Incorporating texture into classification of forest species composition from airborne multispectral images. International Journal of Remote Sensing, 21, pp. 61-79.

Grashof-Bokdam, C. and Langevelde, F. 2005, Green veining: landscape determinants of biodiversity in European agricultural landscapes. Landscape Ecology, 20, pp. 417-439.

Haralick, R., 1979, Statistical and structural approaches to texture. Proceedings of the IEEE, 67, pp. 786-804. 
Haralick, R.M., Shanmugan, K. and Dinstein, I., 1973, Texture features for image classification. IEEE Transactions on Systems, Man and Cybernetics, 3, pp. 610-621.

Kayitakire, F., Hamel, C. and Defourny, P., 2006, Retrieving forest structure variables based on image texture analysis and IKONOS-2 imagery. Remote Sensing of Environment, 102, pp. 390-401.

Li, X., Ramachandran, R., Graves, S. and Movva, S., 2006. A hybrid object-based/pixelbased classification approach to detect geophysical phenomena. In Second NASA Data Mining Workshop: Issues and Applications in Earth Science, Pasadena, CA.

Marceau, D.J., Howarth, P.J., Dubois, J.M.M. and Gratton, D.J., 1990, Evaluation of the grey-level co-occurrence matrix-method for land cover classification using SPOT imagery. IEEE Transactions on Geoscience and Remote Sensing, 28, pp. 513-519.

Pekkarinen, L., Reithmaier, P. and Strobl P., 2009, Pan-European Forest/Non-Forest mapping with Landsat ETM+ and CORINE Land Cover 2000 data. ISPRS Journal of Photogrammetry and Remote Sensing, 64, pp. 171-183.

Peterson, U., Pussa, K. and Liira, J. 2004, Issues related to delineation of forest boundaries on Landsat Thematic Mapper winter images. International Journal of Remote Sensing, 25, pp. 5617-5628.

Puissant, A., Hirsch, J. and Weber, C., 2005, The utility of texture analysis to improve perpixel classification for high to very high spatial resolution imagery. International Journal of Remote Sensing, 26, pp. 733-745.

Sarthou, J.P., Ouin, A., Arrignon, F., Barreau, G. and Bouyjou, B., 2005, Landscape parameters explain the distribution and abundance of Episyrphus balteatus (Diptera, Syrphidae). European Journal of Entomology, 102, pp. 539-545.

Shackelford, A.K. and Davis, C.H., 2003, A combined fuzzy pixel-based and object-based approach for classification of high-resolution multispectral data over urban areas, IEEE Transactions on Geoscience and Remote Sensing, 41, pp. 2354-2364.

Stach, N., Barnerias, C. and Dommanget, A., 2006, Hedges and tree rows detection with eCognition for the use of the French national forest inventory. In $1^{\text {st }}$ International Conference on Object-Based Image Analysis, 4-5 July, Salzburg University, Salzburg, Austria.

St Onge, B.A. and Cavayas, F., 1995, Estimating forest stand structure from high resolution imagery using the directional variogram. International Journal of Remote Sensing, 16, pp. 1999-2021.

Thornton, M.W., Atkinson, P.M. and Holland, D.A., 2006, Sub-pixel mapping of rural land cover objects from fine spatial resolution satellite sensor imagery using super-resolution pixel-swapping. International Journal of Remote Sensing, 27, pp. 473-491.

Tuominen, S. and Pekrarinen, A., 2005, Performance of different spectral and textural aerial photograph features in multi-source forest inventory. Remote Sensing of Environment, 94, pp. 256-268.

Vogt, P., Riitters, K.H., Estreguil, C., Kozak, J., Wade, T.G. and Wickham, J.D., 2007, Mapping spatial patterns with morphological image processing. Landscape Ecology, 22, pp. 171-177.

Wang, L., Sousa, W.P. and Gong, P., 2004, Integration of object-based and pixel-based classification for mapping mangroves with IKONOS imagery. International Journal of Remote Sensing, 25, pp. 5655-5668.

Wulder, M., LeDrew, E.F., Franklin, S.E. and Lavigne, M.B., 1998, Aerial image texture information in the estimation of northern deciduous and mixed wood leaf area index (LAI). Remote Sensing of Environment, 64, pp. 64-76.

Zhang, Y., Heipke, C., Butenuth, M. and Hu, X., 2006, Automatic extraction of wind erosion obstacles by integration of GIS data, DSM and stereo images. International Journal of Remote Sensing, 27, pp. 1677-1690. 